\title{
Impact of the Poor Oral Health Status of Children on Their Families: An Analytical Cross-Sectional Study
}

\author{
Mir Faeq Ali Quadri 1 ,*®D, Fatimah Rasheed M. Jaafari ${ }^{2}$, Noha Ahmed A. Mathmi ${ }^{2}$, Nouf Hassan F. Huraysi ${ }^{2}$, \\ Maryam Nayeem ${ }^{3}$, Abbas Jessani ${ }^{4}$, Santosh Kumar Tadakamadla ${ }^{5,6}$ and Jyothi Tadakamadla ${ }^{5}$ \\ 1 Dental Public Health, Department of Preventive Dental Sciences, College of Dentistry, Jazan University, \\ Jazan 45142, Saudi Arabia \\ 2 Dental Intern Trainee, College of Dentistry, Jazan University, Jazan 45142, Saudi Arabia; \\ fatimahRJ@hotmail.com (F.R.M.J.); Noha95@windowslive.com (N.A.A.M.); \\ drnoee1995@gmail.com (N.H.F.H.) \\ 3 Department of Pharmacology, College of Pharmacy, Jazan University, Jazan 45142, Saudi Arabia; \\ maryamnayeem12@gmail.com \\ 4 Schulich School of Medicine and Dentistry, The University of Western Ontario, \\ London, ON N6A 3K7, Canada; abbas.jessani@schulich.uwo.ca \\ 5 School of Medicine and Dentistry, Griffith University, Gold Coast 4222, Australia; \\ santoshkumar.tadakamadla@griffithuni.edu.au (S.K.T.); jyothi.tadakamadla@griffithuni.edu.au (J.T.) \\ 6 Menzies Health Institute Queensland, Gold Coast 4222, Australia \\ * Correspondence: dr.faeq.quadri@gmail.com
}

check for updates

Citation: Quadri, M.F.A.; Jaafari, F.R.M.; Mathmi, N.A.A.; Huraysi, N.H.F.; Nayeem, M.; Jessani, A.; Tadakamadla, S.K.; Tadakamadla, J. Impact of the Poor Oral Health Status of Children on Their Families: An Analytical Cross-Sectional Study. Children 2021, 8, 586. https:// doi.org/10.3390/children8070586

Academic Editor: Diana Ram

Received: 20 June 2021

Accepted: 7 July 2021

Published: 9 July 2021

Publisher's Note: MDPI stays neutral with regard to jurisdictional claims in published maps and institutional affiliations.

Copyright: (c) 2021 by the authors. Licensee MDPI, Basel, Switzerland. This article is an open access article distributed under the terms and conditions of the Creative Commons Attribution (CC BY) license (https:// creativecommons.org/licenses/by/ $4.0 /)$.

\begin{abstract}
The impact of poor oral health may not just be limited to the children themselves but can impact their families. The current study aims to perform psychometric analyses of the Arabic version of the Family Impact Scale and investigate the association of its domains with the oral health status of children. This cross-sectional study was carried out in a sample of 500 parent-child dyads from high schools of Jazan city of the Kingdom of Saudi Arabia. The Arabic version of the Family Impact Scale was subjected to reliability and validity tests. The explanatory variables in the current study are: the oral health status, parents combined income, parents' education, age and sex of the child. The descriptive analysis was reported using proportions, this was followed by the bivariate and multivariable analyses. About $24.2 \%$ of children were reported to have fair, poor, and very poor oral health. A lower frequency of family impact corresponded with better oral health $(\mathrm{OH})$ status of children $(p<0.001)$. The likelihood of parent's taking time off from work and having financial difficulties was nearly two-times greater if their children had poor oral health. Similarly, interruption in sleep and other normal activities of parents is four times and five times greater, respectively, if the child has poor oral health status. Thus, the poor oral health of school children in the Jazan region of Saudi Arabia is a matter of grave concern as it is observed to be associated with family impacts; particularly affecting the parent's work, sleep, and other normal family activities.
\end{abstract}

Keywords: oral health; children; impact; parents; families; Saudi Arabia

\section{Background}

Oral health conditions are identified in population studies using clinical measures such as the decayed, missing, and filled teeth (DMFT) index for dental caries, or the Dental Aesthetic Index (DAI) for malocclusion. These indices are useful in reporting the prevalence and severity of the oral health status. However, the clinical reporting is less useful to reflect the end-point or the impact of diseases. The World Health Organization (WHO) has considered the oral health-related quality of life (OHRQoL) construct as an integral part of the Global Oral Health Program and as a fundamental measure of an individual's oral health and well-being [1]. The OHRQoL has been assessed and appraised in various populations and it presents semi-qualitative participant-based ratings of oral 
health status involving multidimensional characteristics in comparison to the traditional clinical observations [2].

Currently, it is well-understood that untreated oral health conditions may result in impaired daily activities including poor sleeping and eating [3-6]. However, the impact of oral health conditions may not just be limited to the children themselves but can impact their families [7-9]. For instance, thought of failure to instil good oral health practices in their children leading to the oral diseases may render guilt and distress among the parents. Besides, the visit to a dental health care service provider to seek dental treatment for their children by taking time out of their working hours may affect them financially $[10,11]$.

Earlier, Locker and colleagues [12], in agreement with Rothman and colleagues [13], stated that there are several reasons behind the inclusion of the Family Impact Scale in the health-related quality of life instruments. First, the vital role played by parents and caregivers in the health of children; second, the possibility that the long-term disease condition will affect the parents and caregivers; third, the treatments to illnesses mostly address the family needs and concerns along with the child's; fourth, the fact that the caregiver- or parent-perceived health of children may be persuaded by the level of physical and emotional influence on them by the health of a child.

Recently, Kumar and colleagues further emphasized the inclusion of family impacts and additionally reported that the caregiver burden in subjective measures can be addressed if the parental reports of the child's health are assessed alongside [14]. Therefore, the family impacts is an important outcome measure that may be associated with oral health conditions in children [15]. Providing such measures that reflect the consequences of untreated oral diseases may contribute to a paradigm shift towards the impact of oral diseases and the assessment of the biopsychosocial approach to oral health care [2]. This will augment the data on oral health of children in and around a country or region, and help the public health practitioners to advocate the prevention strategies more effectively.

The Jazan region of Saudi Arabia needs effective oral disease prevention strategies. The oral health of school children in this region has been assessed previously and is observed to be rather poor. In a study that sampled 520 boys and 333 girls from the Jazan region, nearly $91 \%$ of them had at least one decayed tooth in their oral cavity [16]. These results were consistent with another recent study that utilized self-perceived measure to assess the teeth condition of school-going children [17]. However, the OHRQoL construct and subsequently the Family Impact Scale has not been administered in this region, thus portraying the dearth of imperative evidence. Moreover, within the 25 Arabic speaking nations across the globe, there is no Arabic version of the Family Impact Scale. Thus, the current study aims to perform psychometric analyses of the Arabic version of the Family Impact Scale and investigate the association of its domains with the oral health status of children.

\section{Methodology}

\subsection{Ethical Considerations}

The current study is carried out in accordance with the Declaration of Helsinki and the Human Research and Ethics Committee of the Jazan University, Saudi Arabia approved the study protocol (Approval record: REC42/1/090). Each participant was recruited in the study only after providing signed informed consent.

\subsection{Study Design, Participants, and Sampling}

The current cross-sectional study design comprises two phases. In phase 1, the original English version of the Family Impact Scale was subjected to psychometric analyses. For the cross-cultural adaptation, the current study followed the procedure specified in an earlier report [14]. The original scale was translated into Arabic by a practicing dentist who is familiar with both languages (English and Arabic). Another bilingual dentist was asked to reverse translate the Arabic version to English and the translated documents were presented in a virtual meeting to discuss and sort the discrepancies. The translated Arabic 
version was then shared with school teachers $(n=2)$ and parents $(n=2)$ to obtain their view on the clarity of each item. It was enquired if the items were confusing, upsetting, and difficult in terms of understanding or wording. There was no difficulty reported, thus, completing the translation procedure. Forty parents, who were not part of the later investigations received the questionnaire twice with a gap of two weeks to compute the test-retest reliability.

In phase 2, the tested questionnaire was distributed to the study participants. The process involved creating an online survey and disseminating the link to the parents of the primary school children of Jazan city, targeting only the Saudi Nationals; this contributed to the homogeneity of the study sample. The link which was created using Google Forms was circulated using email or the WhatsApp messaging service with the help of the school administration staff. The landing page of the survey indicated that completion and submission of the online survey implied the formal consent of the parent.

The sample size calculation for phase 2 was estimated using the values from a prior study, where $80.3 \%$ of children were found to have poor oral health [17]. The precision and power of the study was set at 0.05 (type- 1 error) and $80 \%$, respectively. After accounting for about $20 \%$ of non-respondents, the required sample size was 294 . However, nearly 500 parents from eight sex-segregated schools in Jazan city provided their responses and were included in the study. We included more than the calculated sample size to increase the power of the study and also to have a more representative sample.

\subsection{Study Variables}

The impacts on the family were considered as the outcome variable in the current study and the data were collected using the Family Impact Scale (FIS) [12] of the ParentalCaregiver Perceptions Questionnaires (P-CPQ) [18]. The FIS questionnaire includes items on parental/family activity (five questions); parental emotions (four questions); family conflicts (four questions); and financial burden (one question). The explanatory variables included child oral health status as perceived by their parents (responses: very poor, poor, fair, good, very good), parents combined income ( $\leq$ SAR10,000, >SAR 10,000 per month), parents' education (did not attend/complete school, completed schooling, completed graduate-level education), age of the child (in years), and sex of child (boy or girl).

\subsection{Statistical Analysis}

The convergent validity of the Arabic version was computed by assessing the correlations (Spearman's Correlation Coefficient) of subscale and overall scores with global ratings of oral health. A value below 0.20 was regarded as weak, between 0.20 and 0.30 as a medium, and from 0.30 onwards as high [19]. Internal consistency of subscale and overall subscale was computed using Cronbach's alpha; a value of 0.70 and more was considered acceptable [14]. Intra-class correlation coefficient (ICC) was used to report test-retest reliability and a value of 0.80 was considered as good and more than 0.80 as excellent [20]. The descriptive analysis is reported using proportions, this is followed by computing the unadjusted and adjusted odds ratio estimates. The outcome and explanatory variable i.e., family impacts and oral health status were recategorized into dichotomous before carrying out the binary logistic regression analyses. The final analyses were adjusted for the sociodemographic characteristics. All analyses were carried out using the SPSS version 25.0 (IBM, New York, NY, USA).

\section{Results}

Parents (mother or father) of 500 children (55.6\% boys and $44.4 \%$ girls) responded to the questionnaire. Nearly a quarter $(24.2 \%)$ of children were reported to have fair, poor, and very poor oral health. The descriptive findings are presented in Table 1 . The findings from the family impact scale indicated that due to poor oral health of children, about $21 \%$ of parents had to take time off from their work, $36.8 \%$ commented that their children needed more attention, $24.4 \%$ had less time for themselves, $37.6 \%$ had sleeping problems, and 
$16.8 \%$ had financial difficulties. About $22 \%$ of children feel jealous and $16.8 \%$ blame parents for their poor oral health.

Table 1. Descriptive characteristics of the study sample $(n=500)$.

\begin{tabular}{|c|c|}
\hline Study Variables & $n(\%)$ \\
\hline \multicolumn{2}{|l|}{ Sex } \\
\hline Girl & $278(55.6 \%)$ \\
\hline Boy & $222(44.4 \%)$ \\
\hline \multicolumn{2}{|c|}{ Parent-perceived oral health } \\
\hline Very poor & $7(1.4 \%)$ \\
\hline Poor & $13(2.6 \%)$ \\
\hline Fair & $101(20.2 \%)$ \\
\hline Good & $135(27 \%)$ \\
\hline Very good & $242(48.4 \%)$ \\
\hline \multicolumn{2}{|l|}{ FIS } \\
\hline \multicolumn{2}{|c|}{ Father or Mother took time off from work } \\
\hline No & $396(79.2 \%)$ \\
\hline Yes & $104(20.8 \%)$ \\
\hline \multicolumn{2}{|c|}{ Child needed more attention from parents } \\
\hline No & $316(63.2 \%)$ \\
\hline Yes & $184(36.8 \%)$ \\
\hline \multicolumn{2}{|c|}{ Less self-time for parents } \\
\hline No & $378(75.6 \%)$ \\
\hline Yes & $122(24.4 \%)$ \\
\hline \multicolumn{2}{|c|}{ Sleeping problems for parents } \\
\hline No & $312(62.4 \%)$ \\
\hline Yes & $188(37.6 \%)$ \\
\hline \multicolumn{2}{|c|}{ Interruption to family activities } \\
\hline No & $434(86.8 \%)$ \\
\hline Yes & $66(13.2 \%)$ \\
\hline \multicolumn{2}{|l|}{ Parent's feeling upset } \\
\hline No & $414(82.8 \%)$ \\
\hline Yes & $86(17.2 \%)$ \\
\hline \multicolumn{2}{|l|}{ Parent's feeling guilty } \\
\hline No & $393(78.6 \%)$ \\
\hline Yes & $107(21.4 \%)$ \\
\hline \multicolumn{2}{|c|}{ Have fewer opportunities in life } \\
\hline No & $407(81.4 \%)$ \\
\hline Yes & $93(18.6 \%)$ \\
\hline \multicolumn{2}{|c|}{ Feel uncomfortable in public places } \\
\hline No & $380(76 \%)$ \\
\hline Yes & $120(24)$ \\
\hline
\end{tabular}


Table 1. Cont.

\begin{tabular}{cc}
\hline Study Variables & $\boldsymbol{n ( \% )}$ \\
\hline Child argues & $406(81.2 \%)$ \\
\hline No & $94(18.8 \%)$ \\
\hline Yes & $390(78 \%)$ \\
\hline Child feels jealous & $110(22 \%)$ \\
\hline No & $445(89 \%)$ \\
\hline Yes & $55(11 \%)$ \\
\hline Conflict in family & $429(85.8 \%)$ \\
\hline No & $71(14.2 \%)$ \\
\hline Yes & \\
\hline Child blames parents & $416(83.2 \%)$ \\
\hline No & $84(16.8 \%)$ \\
\hline Yes & \\
\hline Financial difficulties & \\
\hline No & \\
\hline Yes & \\
\hline
\end{tabular}

The findings from discriminant validity tests showed a significant gradient in mean FIS scores across various categories of oral health status (Table 2). The overall scale demonstrated a Cronbach's alpha value of 0.86 , indicating a high internal consistency. Similarly, the subscales also showed moderate to high internal consistency; the financial burden subscale showed excellent internal consistency. The test-retest reliability based on the forty recruited parents indicated a perfect agreement (0.90), and similar were the results across the subscales of FIS (Table 3).

Table 2. Findings from discriminant validity of the overall and subscale scores by perceived oral health status.

\begin{tabular}{|c|c|c|c|c|c|c|c|c|c|c|}
\hline \multirow{2}{*}{$\begin{array}{l}\text { Oral Health } \\
\text { Status }\end{array}$} & \multicolumn{2}{|c|}{ FIS Overall Score } & \multicolumn{2}{|c|}{ Parental Activities } & \multicolumn{2}{|c|}{ Parental Emotions } & \multicolumn{2}{|c|}{ Family Conflict } & \multicolumn{2}{|c|}{ Financial Burden } \\
\hline & Median & $\begin{array}{l}\text { Mean } \\
\text { (SD) }\end{array}$ & Median & $\begin{array}{c}\text { Mean } \\
\text { (SD) }\end{array}$ & Median & $\begin{array}{c}\text { Mean } \\
\text { (SD) }\end{array}$ & Median & $\begin{array}{l}\text { Mean } \\
\text { (SD) }\end{array}$ & Median & $\begin{array}{l}\text { Mean } \\
\text { (SD) }\end{array}$ \\
\hline Very poor & 7.5 & $8.0(7.3)$ & 6.0 & $5.0(4.8)$ & 6.0 & $5.1(4.0)$ & 7.0 & $6.0(4.8)$ & 8.0 & $8.0(4.8)$ \\
\hline Poor & 6.5 & $7.7(6.0)$ & 5.0 & $3.6(3.3)$ & 4.0 & $4.6(3.0)$ & 6.0 & $5.6(3.3)$ & 6.0 & $7.6(3.3)$ \\
\hline Fair & 5.0 & $7.0(7.6)$ & 4.5 & $3.1(3.2)$ & 3.5 & $3.1(3.2)$ & 5.5 & $4.1(3.2)$ & 5.5 & $5.1(3.2)$ \\
\hline Good & 2.0 & $3.0(5.9)$ & 2.0 & $3.0(3.9)$ & 2.0 & $3.9(3.0)$ & 2.5 & $2.0(3.9)$ & 2.0 & $3.0(3.9)$ \\
\hline Very good & 1.5 & $2.5(4.1)$ & 1.0 & $2.5(3.0)$ & 1.5 & $2.5(2.0)$ & 1.5 & $1.5(3.0)$ & 1.0 & $1.5(3.0)$ \\
\hline
\end{tabular}

Table 3. Internal consistency and intra class correlation coefficient of the family impact scale.

\begin{tabular}{ccc}
\hline FIS & Internal Consistency (Cronbach's Alpha) & $\begin{array}{c}\text { Intraclass Correlation Coefficient } \\
\text { (ICC, 95\% CI) }\end{array}$ \\
\hline Overall scale & 0.86 & $0.90(0.80,0.93)$ \\
\hline Subscales & & $0.92(0.68,0.96)$ \\
\hline Parental activity & 0.87 & $0.76(0.58,0.84)$ \\
\hline Parental emotions & 0.77 & $0.82(0.58,0.90)$ \\
\hline Family conflict & 0.80 & $0.92(0.68,0.94)$ \\
\hline Financial burden & 0.90 & 0.90 \\
\hline
\end{tabular}


The analysis in Table 4 indicates that a lower frequency of family impact corresponds to better oral health status of children $(p<0.001)$. This finding is consistent with each of the item in the family impact scale. Table 5 presents the association between the oral health status of children and the family impacts after adjusting for confounders. The likelihood of parent's taking time off from work and having financial difficulties is nearly two-times greater if their children had poor oral health. Similarly, interruption in sleep and other normal activities of parents is four times and five times greater, respectively, if their children have poor oral health.

Table 4. Distribution of family impacts by the oral health status of children $(n=500)$.

\begin{tabular}{|c|c|c|c|c|c|c|}
\hline \multirow{2}{*}{ Family Impact Scale } & \multicolumn{5}{|c|}{ Oral Health Status } & \multirow{2}{*}{$p$-Value } \\
\hline & Very Poor & Poor & Fair & Good & Very Good & \\
\hline \multicolumn{7}{|c|}{ Father or Mother taken time off from work } \\
\hline No & $1(0.2 \%)$ & $5(1 \%)$ & $57(11.4 \%)$ & $108(21.6 \%)$ & $223(44.6 \%)$ & \multirow{2}{*}{$<0.001$} \\
\hline Yes & $6(1.2 \%)$ & $8(1.6 \%)$ & $44(8.8 \%)$ & $27(5.4 \%)$ & $19(3.8 \%)$ & \\
\hline \multicolumn{7}{|c|}{ Child needed more attention from parents } \\
\hline No & $3(0.6 \%)$ & $3(0.6 \%)$ & $46(9.2 \%)$ & $85(17 \%)$ & $178(35.6 \%)$ & \multirow{2}{*}{$<0.001$} \\
\hline Yes & $4(0.8 \%)$ & $10(2 \%)$ & $55(11 \%)$ & $50(10 \%)$ & $64(12.8 \%)$ & \\
\hline \multicolumn{7}{|l|}{ Less self-time for parents } \\
\hline No & $5(1 \%)$ & $8(1.6 \%)$ & $64(12.8 \%)$ & $96(19.2 \%)$ & $204(40.8 \%)$ & \multirow[b]{2}{*}{$<0.001$} \\
\hline Yes & $2(0.4 \%)$ & $5(1 \%)$ & $37(7.4 \%)$ & $39(7.8 \%)$ & $38(7.6 \%)$ & \\
\hline \multicolumn{7}{|c|}{ Sleeping problems for parents } \\
\hline $\begin{array}{llll}1 & \text { No } & \text { No }\end{array}$ & $2(0.4 \%)$ & $3(0.6 \%)$ & $43(8.6 \%)$ & $82(16.4 \%)$ & $182(36.4 \%)$ & \multirow{2}{*}{$<0.001$} \\
\hline Yes & $5(1 \%)$ & $10(2 \%)$ & $58(11.6 \%)$ & $53(10.6 \%)$ & $60(12 \%)$ & \\
\hline \multicolumn{7}{|c|}{ Interruption to family activities } \\
\hline No & $3(0.6 \%)$ & $11(2.2 \%)$ & $79(15.8 \%)$ & $119(23.8 \%)$ & $220(44 \%)$ & \multirow[b]{2}{*}{$<0.001$} \\
\hline Yes & $4(0.8 \%)$ & $2(0.4 \%)$ & $22(4.4 \%)$ & $16(3.2 \%)$ & $22(4.4 \%)$ & \\
\hline \multicolumn{7}{|l|}{ Parent's feeling upset } \\
\hline No & $5(1 \%)$ & $5(1 \%)$ & $79(15.8 \%)$ & $107(21.4 \%)$ & $216(43.2 \%)$ & \multirow{2}{*}{$<0.001$} \\
\hline Yes & $2(0.4 \%)$ & $8(1.6 \%)$ & $22(4.4 \%)$ & $28(5.6 \%)$ & $26(5.2 \%)$ & \\
\hline \multicolumn{7}{|l|}{ Parent's feeling guilty } \\
\hline No & $2(0.4 \%)$ & $7(1.4 \%)$ & $60(12 \%)$ & $105(21 \%)$ & $217(43.4 \%)$ & \multirow{2}{*}{$<0.001$} \\
\hline Yes & $5(1 \%)$ & $6(1.2 \%)$ & $41(8.2 \%)$ & $30(6 \%)$ & $25(5 \%)$ & \\
\hline \multicolumn{7}{|c|}{ Have fewer opportunities in life } \\
\hline No & $5(1 \%)$ & $8(1.6 \%)$ & $74(14.8 \%)$ & $104(20.8 \%)$ & $214(42.8 \%)$ & \multirow{2}{*}{$<0.001$} \\
\hline Yes & $2(0.4 \%)$ & $5(1 \%)$ & $27(5.4 \%)$ & $31(6.2 \%)$ & $28(5.6 \%)$ & \\
\hline \multicolumn{7}{|c|}{ Feel uncomfortable in public places } \\
\hline No & $1(0.2 \%)$ & $8(1.6 \%)$ & $72(14.4 \%)$ & $102(20.4 \%)$ & $195(39 \%)$ & \multirow{2}{*}{$<0.001$} \\
\hline Yes & $6(1.2 \%)$ & $5(1 \%)$ & $29(5.8 \%)$ & $33(6.6 \%)$ & $47(9.45 \%)$ & \\
\hline \multicolumn{7}{|l|}{ Child argues } \\
\hline No & $3(0.6 \%)$ & $8(1.6 \%)$ & $74(14.8 \%)$ & $102(20.4 \%)$ & $217(43.4 \%)$ & \multirow{2}{*}{$<0.001$} \\
\hline Yes & $4(0.8 \%)$ & $5(1 \%)$ & $27(5.4 \%)$ & $33(6.6 \%)$ & $25(5 \%)$ & \\
\hline \multicolumn{7}{|l|}{ Child feels jealous } \\
\hline No & $4(0.8 \%)$ & $8(1.6 \%)$ & $69(13.8 \%)$ & $97(19.4 \%)$ & $210(42.5 \%)$ & $<0.001$ \\
\hline
\end{tabular}

Table 5. Logistic regression models demonstrating the impact of poor oral health status of children on selected items in the family impact scale $(n=500)$.

\begin{tabular}{|c|c|c|c|c|}
\hline Oral Health Status & $\begin{array}{c}\text { Unadjusted OR } \\
(95 \% \mathrm{CI})\end{array}$ & $p$-Value & $\begin{array}{c}\text { Adjusted OR } \\
(95 \% \mathrm{CI})\end{array}$ & $p$-Value \\
\hline \multicolumn{5}{|c|}{ Time off from work } \\
\hline Good & 1.00 & & 1.00 & \\
\hline Poor & $1.9(1.02,2.72)$ & $<0.001$ & $2.1(1.16,2.54)$ & $<0.001$ \\
\hline \multicolumn{5}{|c|}{ Financial difficulties } \\
\hline Good & 1.00 & & 1.00 & \\
\hline Poor & $2.3(1.45,3.62)$ & $<0.001$ & $1.9(1.49,2.51)$ & $<0.001$ \\
\hline
\end{tabular}


Table 5. Cont.

\begin{tabular}{|c|c|c|c|c|}
\hline Oral Health Status & $\begin{array}{l}\text { Unadjusted OR } \\
(95 \% \mathrm{CI})\end{array}$ & $p$-Value & $\begin{array}{c}\text { Adjusted OR } \\
(95 \% \mathrm{CI})\end{array}$ & $p$-Value \\
\hline \multicolumn{5}{|c|}{ Child need more attention } \\
\hline Good & 1.00 & & 1.00 & \\
\hline Poor & $4.1(2.27,7.26)$ & $<0.001$ & $4.0(2.15,7.75)$ & $<0.001$ \\
\hline \multicolumn{5}{|c|}{ Parent's sleep disturbed } \\
\hline Good & 1.00 & & 1.00 & $<0.001$ \\
\hline Poor & $5.1(2.73,9.50)$ & $<0.001$ & $4.9(2.80,8.76)$ & \\
\hline \multicolumn{5}{|c|}{ Interruption of normal activities } \\
\hline Good & 1.00 & & 1.00 & \\
\hline Poor & $4.5(2.30,9.01)$ & $<0.001$ & $3.1(2.78,6.76)$ & $<0.001$ \\
\hline \multicolumn{5}{|c|}{ Parent's feel guilty } \\
\hline Good & 1.00 & & 1.00 & \\
\hline Poor & $5.4(2.90,9.10)$ & $<0.001$ & $6.4(3.30,9.26)$ & $<0.001$ \\
\hline
\end{tabular}

Good oral health status is summarized by including the responses good and very good. Poor oral health status is summarized by including the responses fair, poor, and very poor. ${ }^{*} \mathrm{OR}$ analyses are adjusted for parent's education and income.

\section{Discussion}

A child does not live in isolation; poor oral health may not just directly impact them physically, emotionally, and socially; leading to impaired nutrition, communication, school attendance, self-esteem etc., but could also present a more distal affect related to their parents and families. Thus, untreated oral health conditions may have wider repercussions, measuring this impact is particularly relevant, as it will assist the researchers and policymakers in advocating and raising awareness for preventing oral diseases. The current study validates the Arabic version of the Family Impact Scale. The internal consistency and the test-retest reliability was excellent, and the hypothesis relating to the construct validity was successfully affirmed. These findings were consistent with earlier reports from Canada [12], India [14], Italy [21], Saudi Arabia [22], and Brazil [23]. Many of the earlier reports utilized the clinical oral health data which are supposedly a better measure in comparison to self- or parent-perceived measures. However, given the current pandemic situation (COVID-19) and that the schools followed a distant-learning process, it was not feasible to clinically examine the oral health statuses of children. Thus, the link to the questionnaire was emailed or sent through the WhatsApp messaging service. Nevertheless, parent's perception to determine oral health status of children has been used earlier and found to somewhat represent the clinically examined oral health status $[17,24,25]$. Findings show that, because of the poor oral health condition of children, the parents reported the need to take time off from work, impaired sleep and regular activities, and financial distress, and this result was similar to the response received from parents residing in a more developed country with higher Gross Domestic Product (GDP) and a better healthcare infrastructure [26].

Nearly a quarter of the children in the current study were reported by their parents to have poor oral health. This is undervalued in comparison to the reports from research carried out in a similar study setting where a greater proportion of children had poor teeth and gum conditions $[17,27]$ and the underestimation can be attributed to the lower oral health literacy among the adults residing in the Jazan region of Saudi Arabia [28]. Findings also show that poor oral health in children is significantly related to all the domains of the family impact scale, implying that the poor oral health status of children significantly impacts the daily life and well-being of their parents. Interestingly, the poor oral health of children was associated with greater odds of financial difficulty to parents, and this is despite free oral health treatment facilities available in the region. Parents also reported 
guilt and stress because of the oral health status of their children, and this may be due to the disability caused because of pain and infection related to untreated oral health conditions. Most of the findings demonstrated a better precision after adjusting for the socio-economic status of parents. Abed and colleagues demonstrated similar findings using a much larger sample size in a nationwide study carried out in the United Kingdom [26].

One of the strengths of the current study was that the sample size was larger than what was required, contributing to adequate power of the study and a significant representation of high school children in the region. Next, a tested assessment tool was used to gather data adding to the reliability and validity of the findings. Lastly, the sample consisted of only Arab nationals which stipulated a homogenous study sample, thus, covering for bias arising due to culturally different oral hygiene practices. However, the current study is cross-sectional and may not indicate a causal association between oral health and family impacts. The selection of sample was non-random and this may affect the generalization of the findings. Nevertheless, the sample participation rate was good, and the current study did not intend to report any population estimates but aimed to investigate the impact of oral health status on the child's families. Additionally, findings from clinical oral health examinations would have yielded more accurate data on oral health, but this was not feasible given the current pandemic situation. Nonetheless, the subjective assessment of oral health is followed by many research studies measuring the OHRQoL of children, and the findings are somewhat consistent with the clinical reports [29-31]. Despite the limitations, the current study yields important findings which may significantly contribute to the lack of literature from Arab populations.

In conclusion, the poor oral health of schoolchildren in the Jazan region is a matter of grave concern. It is associated with family impacts; particularly affecting the parent's work, sleep, normal family activities, leading to distress and guilt. Thus, attending to oral diseases can have positive effects on children and their families. Further investigations using longitudinal study designs and in different study setting are required to substantiate the findings.

Author Contributions: M.F.A.Q., F.R.M.J., N.A.A.M. and N.H.F.H. conceived the study. F.R.M.J., N.A.A.M. and N.H.F.H. collected the data. M.F.A.Q. carried out the analyses, and result interpretation was completed by M.F.A.Q., A.J., S.K.T. and J.T. Then, M.F.A.Q. and M.N. prepared the first draft, and all authors contributed significantly in the subsequent drafts and gave their final approval. All authors have read and agreed to the published version of the manuscript.

Funding: This research is self-funded and not supported by any external organization.

Institutional Review Board Statement: The study was conducted according to the guidelines of the Declaration of Helsinki, and was approved by the Institutional Review Board at Jazan University, Saudi Arabia on 22 March 2021 (Approval record: REC42/1/090).

Informed Consent Statement: Written informed consent was obtained from children and their parents before the commencement of data collection.

Data Availability Statement: The data is available upon reasonable request.

Acknowledgments: The authors would like to extend their gratitude to the children and parents who took part in this study.

Conflicts of Interest: The authors report no conflict of interest and are solely responsible for the content and writing of the paper.

\section{References}

1. Petersen, P.E. The World Oral Health Report 2003: Continuous improvement of oral health in the 21st century-The approach of the WHO Global Oral Health Programme. Community Dent. Oral Epidemiol. 2003, 31 (Suppl. 1), 3-23. [CrossRef] [PubMed]

2. Sischo, L.; Broder, H.L. Oral health-related quality of life: What, why, how, and future implications. J. Dent. Res. 2011, 90, 1264-1270. [CrossRef] 
3. Zaror, C.; Pardo, Y.; Espinoza-Espinoza, G.; Pont, À.; Muñoz-Millán, P.; Martínez-Zapata, M.J.; Vilagut, G.; Forero, C.G.; Garin, O.; Alonso, J.; et al. Assessing oral health-related quality of life in children and adolescents: A systematic review and standardized comparison of available instruments. Clin. Oral Investig. 2018. [CrossRef] [PubMed]

4. Amilani, U.; Jayasekara, P.; Perera, I.R.; Carter, H.E.; Senanayake, S.; Kularatna, S. Oral impact on daily performance (OIDP) scale for use in Sri Lankan adolescents: A cross sectional modification and valida-tion study. BMC Oral Health 2020, 20, 16. [CrossRef]

5. Zaror, C.; Matamala-Santander, A.; Ferrer, M.; Rivera-Mendoza, F.; Espinoza-Espinoza, G.; Martínez-Zapata, M.J. Impact of early childhood caries on oral health-related quality of life: A systematic review and meta-analysis. Int. J. Dent. Hyg. 2021. [CrossRef]

6. Hettiarachchi, R.M.; Kularatna, S.; Byrnes, J.; Scuffham, P.A. Pediatric Quality of Life Instruments in Oral Health Research: A Systematic Review. Value Health 2019, 22, 129-135. [CrossRef]

7. Al-Riyami, I.A.; Thomson, W.M.; Al-Harthi, L.S. Testing the Arabic short form versions of the Parental-Caregivers Perceptions Questionnaire and the Family Impact Scale in Oman. Saudi Dent. J. 2016, 28, 31-35. [CrossRef]

8. Tadakamadla, S.K.; Mangal, G.; Quadri, M.F.A.; Nayeem, M.; Tadakamadla, J. Psychometric Analyses of the Indian (Hindi) Version of the Child Perception Questionnaire (CPQ11-14). Children 2020, 7, 175. [CrossRef]

9. Thomson, W.M.; Foster Page, L.A.; Gaynor, W.N.; Malden, P.E. Short-form versions of the Parental-Caregivers Perceptions Questionnaire and the Family Impact Scale. Community Dent. Oral Epidemiol. 2013, 41, 441-450. [CrossRef]

10. Ramos-Jorge, J.; Paiva, S.; Tataounoff, J.; Pordeus, I.; Marques, L.; Ramos-Jorge, M. Impact of treated/untreated traumatic dental injuries on quality of life among Brazilian schoolchildren. Dent. Traumatol. 2014, 30, 27-31. [CrossRef]

11. Abanto, J.; Carvalho, T.S.; Mendes, F.M.; Wanderley, M.T.; Bönecker, M.; Raggio, D.P. Impact of oral diseases and disorders on oral health-related quality of life of preschool children. Community Dent. Oral Epidemiol. 2010, 39, 105-114. [CrossRef] [PubMed]

12. Locker, D.; Jokovic, A.; Stephens, M.; Kenny, D.; Tompson, B.; Guyatt, G. Family impact of child oral and oro-facial conditions. Community Dent. Oral Epidemiol. 2002, 30, 438-448. [CrossRef]

13. Rothman, M.L.; Hedrick, S.C.; Bulcroft, K.A.; Hickam, D.H.; Rubenstein, L.Z. The validity of proxy-generated scores as measures of patient health status. Med. Care 1991, 29, 115-124. [CrossRef] [PubMed]

14. Kumar, S.; Kroon, J.; Lalloo, R.; Johnson, N.W. Psychometric Properties of Translation of the Child Perception Questionnaire (CPQ11-14) in Telugu Speaking Indian Children. PLoS ONE 2016, 11, e0149181. [CrossRef] [PubMed]

15. Osman, L.; Silverman, M. Measuring quality of life for young children with asthma and their families. Eur. Respir. J. 1996, 21, 35s-41s.

16. Quadri, F.; Hendriyani, H.; Pramono, A.; Jafer, M. Knowledge, attitudes and practices of sweet food and beverage consumption and its association with dental caries among schoolchildren in Jazan, Saudi Arabia. East. Mediterr. Health J. 2015, $21,403-411$. [CrossRef]

17. Bokhari, A.M.; Quadri, M.F.A. What factors contribute to the self-reported oral health status of Arab adolescents? An assessment using a validated Arabic-WHO tool for child oral health (A-OHAT). BMC Oral Health 2020, 20, 21. [CrossRef]

18. Jokovic, A.; Locker, D.; Stephens, M.; Kenny, D.; Tompson, B.; Guyatt, G. Validity and reliability of a questionnaire for measuring child oral-health-related quality of life. J. Dent. Res. 2002, 81, 459-463. [CrossRef]

19. Hemphill, J.F. Interpreting the magnitudes of correlation coefficients. Am. Psychol. 2003, 58, 78-79. [CrossRef]

20. Bartko, J.J. The intraclass correlation coefficient as a measure of reliability. Psychol. Rep. 1966, 19, 3-11. [CrossRef]

21. Kolk, A.M.; Schipper, J.L.; Hanewald, G.J.; Casari, E.F.; Fantino, A.G. The Impact-on-Family Scale: A test of invariance across culture. J. Pediatr. Psychol. 2000, 25, 323-329. [CrossRef]

22. Baghdadi, Z.D. Effects of dental rehabilitation under general anesthesia on children's oral health-related quality of life using proxy short versions of OHRQoL instruments. Sci. World J. 2014, 2014, 308439. [CrossRef]

23. Barbosa, T.D.S.; Gavião, M.B. Evaluation of the Family Impact Scale for use in Brazil. J. Appl. Oral Sci. 2009, 17, $397-403$. [CrossRef]

24. Blumenshine, S.L.; Vann, W.F., Jr.; Gizlice, Z.; Lee, J.Y. Children's school performance: Impact of general and oral health. J. Public Health Dent. 2008, 68, 82-87. [CrossRef]

25. Jackson, S.L.; Vann, W.F., Jr.; Kotch, J.B.; Pahel, B.T.; Lee, J.Y. Impact of poor oral health on children's school attendance and performance. Am. J. Public Health 2011, 101, 1900-1906. [CrossRef]

26. Abed, R.; Bernabe, E.; Sabbah, W. Family Impacts of Severe Dental Caries among Children in the United Kingdom. Int. J. Environ. Res. Public Health 2020, 17, 109. [CrossRef]

27. Quadri, M.F.A.; Shubayr, M.A.; Hattan, A.H.; Wafi, S.A.; Jafer, A.H. Oral Hygiene Practices among Saudi Arabian Children and Its Relation to Their Dental Caries Status. Int. J. Dent. 2018, 2018, 3234970. [CrossRef]

28. Tadakamadla, S.K.; Quadri, M.F.; Pakpour, A.H.; Zailai, A.M.; Sayed, M.E.; Mashyakhy, M.; Inamdar, A.S.; Tadakamadla, J. Reliability and validity of Arabic Rapid Estimate of Adult Literacy in Dentistry (AREALD-30) in Saudi Arabia. BMC Oral Health 2014, 14, 120. [CrossRef] [PubMed]

29. Nurelhuda, N.; Ahmed, M.; Trovik, T.; Astrom, A. Evaluation of oral health-related quality of life among Sudanese schoolchildren using Child-OIDP inventory. Health Qual. Life Outcomes 2010, 8, 152. [CrossRef] [PubMed]

30. Tsakos, G.; Blair, Y.I.; Yusuf, H.; Wright, W.; Watt, R.G.; Macpherson, L.M. Developing a new self-reported scale of oral health outcomes for 5-year-old children (SOHO-5). Health Qual. Life Outcomes 2012, 10, 62. [CrossRef] [PubMed]

31. Yusuf, H.; Gherunpong, S.; Sheiham, A.; Tsakos, G. Validation of an English version of the Child-OIDP index, an oral health-related quality of life measure for children. Health Qual. Life Outcomes 2006, 4, 38. [CrossRef] [PubMed] 